\title{
ROAD TRAFFIC ACCIDENTS IN INDIA: AN OVERVIEW
}

\author{
Thokchom Shantajit ${ }^{1}$, Chirom Ranjeev Kumar ${ }^{1}$, Quazi Syed Zahiruddin ${ }^{2}$ \\ ${ }^{1}$ Resident, ${ }^{2}$ Professor \& Head, Department of Community Medicine, Jawaharlal Nehru Medical College, \\ Datta Meghe Institute of Medical Sciences, Sawangi Meghe, Wardha, Maharashtra, India.
}

\section{ABSTRACT}

Road traffic accidents claim over a million lives every year in the world. As per World Health Organization (WHO) it is one of the leading cause of death. India, being a rapidly developing country with expanding economy has its own issues as regarding road traffic accidents due to rapid proliferation of motorization. Road traffic accidents causes enormous morbidity and mortality and at the same time, the toll on the economy of the country as a result of it is quite heavy. Road traffic accident is a result of an interaction among different factors which include the environment, vehicle and the human being. Traditionally it is considered that road traffic accidents are accidents which are unpredictable, inevitable and not preventable. But road traffic accidents are indeed predictable and preventable in majority of the cases. This require the knowledge of factors contributing and leading to road traffic accidents. There are certain preventive measures which if adopted can lead to decrease in morbidity and mortality resulting from RTA. Hence, it is the responsibility of all to contribute in reducing road traffic accidents.

KEYWORDS: Road traffic accidents; Road traffic injuries; Roads in India, Road safety; Vehicular registration.

\section{INTRODUCTION}

"A road traffic injury is a fatal or non-fatal injury incurred as a result of a collision or incident involving at least one road vehicle in motion on a public road or private road to which the public has right of access resulting in at least one injured or a killed person". [1] Socially these accidents are considered as inevitable and a part of life which occur randomly. But in reality, these are results of a complex set of interaction among the public with their vehicles and the prevalent environmental conditions along with the existing legal provisions. Many a times road traffic accidents are preventable.

Road traffic injury take the lives of nearly 1.3 million people every year and at the same time injure 20-50 million people. According to World Health Organization (WHO), it is the leading cause of death for people aged 15- 29 years. It is projected that road traffic injuries will be among the top five leading cause of death by the year 2030. [2-4]

Underdeveloped and developing countries which constitute $82 \%$ of the world population bear a heavy economic tolls of about 3\% of their GDP due to Road Traffic Accidents (RTA). $90 \%$ of road traffic accidents

$\begin{array}{ll} & \text { DOI: } 10.31878 / \mathrm{ijcbr} .2018 .44 .08 \\ & \\ & \end{array}$

occurs in these countries where the level of motorization accounts for $54 \%$ of world registered vehicle. (3)

India, a rapidly developing country with expanding economy has one of the highest motorization growth rate which is accompanied by rapid expansion in road networks and urbanization. Consequently the country is faced with various issues and impacts of RTA and road safety level. In the year 2015 , the total number of RTA was $5,01,423$ with an increased by $2.5 \%$ in 2014 . These accidents were responsible for a death toll of $1,46,133$ in the year 2015 . The available data translate into $29.9 \%$ persons killed per hundred accidents in the year 2015 in India. Further about 1374 accidents and 400 deaths take place every day on Indian road which translate into 57 accidents and loss of 17 lives every hour on an average in our country. [5-7]

As of 2015 , the total number of registered motor vehicle was $2,10,023,000$. During the same year the road length was 54, 72, 144 kilometers. These road network consist of national highways, state highways, district roads, rural and village roads. Simultaneously the composition of vehicular population as registered were two wheeler $(73.5 \%)$ followed by cars, jeeps and taxis (13.6\%), goods vehicle $(4.4 \%)$, buses $(1 \%)$ and other vehicles $(7.5 \%)$. This result into 167 vehicles per thousand person with a dramatic increased from 8 per thousand person in 1981. (5) The economic loss to the country due to road traffic accident is $3.7 \%$ of GDP. [6]

An important reason for the neglect of road traffic accident in public health is the concept that accidents and injuries are random events. Such events are looked

Corresponding author: Dr. Thokchom Shantajit, Resident, Department of Community Medicine, Jawaharlal Nehru Medical College, Datta Meghe Institute of Medical Sciences, Sawangi Meghe, Wardha, Maharashtra, India.

Email: shantajit.th@gmail.com

International Journal of Clinical and Biomedical Research. (C) 2018 Sumathi Publications.

This is an Open Access article which permits unrestricted non-commercial use, provided the original work is properly cited. 
upon as an inevitable outcomes. They are considered as probably unintended, inevitable and unpredictable; an event that cannot be prevented. $[2,4]$

The leading cause of road traffic accidents in India is mainly due to fault of the driver (77.1\%). Other causes include weather condition, defective motor vehicles, poor condition of the roads etc. [5] These causes are described as below.

\section{Reasons for road traffic accidents in India}

Road traffic accident results from a combination of factors related to the components of the system comprising roads, the environment, vehicles and road users, and the way they interact. These can be grouped under the following heads:

Factors influencing exposure to risk: The mode, mean, duration of travel as well as the layout and design of the road along with insufficient traffic knowledge like speed limits, road sign can have an influence on exposure to risk of road traffic accidents. $[5,6]$

Human Factors in RTA: Drunken Driving, over speeding, decline to follow traffic rules, reckless driving are some of the factors that contribute to road traffic accidents. In India, drunken driving is customary in commercial vehicle drivers. Private car owners and youngsters are also major players in the game. Driver Fatigue, sleepiness, younger age (15-29 years), male sex, inadequate use of helmets and safety belts, medical conditions (sudden illness, myocardial infarction, impaired vision), psychological factors (risk taking, impulsiveness), defective judgment, delayed decisions, aggressiveness, poor perceptions, family dysfunction, and distraction while driving (using mobile phones) also are responsible human factors in RTA. [1, 8, 9]

Environmental risk factors: These are related to the roads like defective and narrow roads, defective layout of crossroads, poor lighting, and lack of familiarity, poor construction, bad design etc. Another factor in India is the outsourcing of road construction to contractors. Some of the contractors are very much profit oriented resulting in low quality roads. Ditches and pot holes also contribute to RTA. [5, 9]

Vehicles factors: Conditions of the vehicles plying on the roads plays a major role in road traffic accidents. Excessive speed, poorly maintained vehicles, large number of vehicles, low driving standards and overloaded buses are some of the factors associated with vehicles. $[5,10]$

Thus, road traffic accidents in India results from an interaction of these different factors.

\section{Preventive measures}

Many road traffic accidents and death are preventable. Some of the preventive measures are briefly outlined below.
Vehicles: Well-maintained vehicles with good breaks, lighting, tyres etc. will reduce accidents. Older vehicles and highly polluting vehicles should be phased out. Vehicles should be provided with seat belts and other necessary safety provisions like airbags. $[2,4,11]$

Environmental factors or Condition of roads: Roads should be well maintained with frequent relaying of road surfaces and markings of road safety signs. Provide proper footpaths for pedestrians and pedestrian crossings at intersections. Provide separate lanes for slow moving and fast moving vehicles. Roads and junctions should be wide and well-lit so that visibility is good. $[1,9,10]$

Human factors: Drivers can significantly contribute to reducing the accidents. Issuing of the driving license should be strictly based on the minimum proficiency acquired by the learners from designated driving schools. All drivers should be properly trained and should possess a valid driving license. Education of the drivers and traveling public about traffic rules should be undertaken. There should be periodic medical checkup especially vision and hearing for the drivers. Indiscriminate honking is to be avoided. Strengthening the penalties/fines (amendment in MVA) for traffic rule violators should be done. There should be stringent checking for overloading. Mandatory registration of criminal cases in overloading can help in reduction of RTA. Ensuring use of road safety devices (helmets, belts, etc.) can be helpful. Overcrowded passenger vehicles should culminate in cancellation of permits. There is a need for a National Accident Relief Policy to ensure: prompt relief, free trauma care, training of police, teachers, paramedics etc.

Rules for compulsory wearing of helmets by two wheelers and seat belts by four wheelers must be implemented. Traffic rules must be strictly enforced by the concerned authorities. Removal of stray animals like cattle and removal of encroachments on footpath and road margins will enable smooth flow of traffic. Preventing haphazard parking of vehicles on busy roads and intersections will ensure free flow of traffic. [4, 5, 9]

\section{Management of accident victims (To reduce mortality)}

The importance of the "Golden Hour" in giving adequate treatment to the accident victim in saving the injured should be highlighted to both the vehicle users and the community. There should be provision of medical care/first aid care facilities on highways and busy roads as well as provision of ambulances and trained health personals in shifting and transporting the injured person to nearby hospitals for treatment. Awareness creation among all sections of the society to treat accident victims with sympathy and without fear so that the morbidity and mortality can be reduced. $[2,8,12]$ 


\section{CONCLUSION}

Road traffic injury take the lives of nearly 1.3 million people every year and at the same time injured 20-50 million people globally. India, being a rapidly developing country has one of the highest motorization growth rate which is accompanied by rapid expansion in road networks and urbanization. Consequently the country is faced with various issues and impacts on road traffic accidents and road safety level. It takes a heavy financial toll on the economy over and above the mortality and morbidity associated with road traffic accidents. Road traffic accidents are predictable and preventable. For it understanding the different factors leading to RTA is a must. Strict implementation of traffic rules and stringent punishments alone will not solve the persisting problem. Change in the mind set of riders and drivers and road users realizing their responsibilities alone will bring about a change. It requires strong political commitment and multipronged strategies to address the current demands and needs of six E's of road safety such as education, engineering (roads), engineering (vehicles), enforcement, emergency care and enactment. We all have a role in preventing RTA.

\section{REFERENCES}

1) Pedestrian safety: A road safety manual for decision-makers and practitioners WHO.2013. available at https://www.who.int/roadsafety/projects/ manuals/pedestrian/en/ Accessed on January 2017.

2) Peden $M M$, World report on road traffic injury prevention: WHO; 2004. 217.

3) Global status report on road safety 2015: supporting a decade of action. WHO; 2015.

4) Decade of Action for Road Safety 2011-2020 Saving millions of lives. WHO

5) Road accidents in India 2016. Government of India, Ministry of road transport \& highways transport research wing, New Delhi, www.morth.nic.in

6) Sharma SM. Road Traffic Accidents in India. Int J Adv Integ Med Sci 2016; 1(2): 57-64.

7) Road accidents in India issues and dimensions. Ministry of road transport \& highways, Government of India; 2015

8) Gopalakrishnan S. A Public Health Perspective of Road Traffic Accidents. J Fam Med Prim Care. 2012;1(2):144.

9) Risk factors for road traffic injuries, Training manual.

How to Cite this article: Thokchom Shantajit, Chirom Ranjeev Kumar, Quazi Syed Zahiruddin. Road traffic accidents in India: An overview. Int. j. clin. biomed. res. 2018;4(4): 36-38. violence_injury_prevention/road_traffic/activities/ roadsafety_training_manual_unit_2.pdf

10) Saving_millions_lives, WHO_en.pdf.

11) Annadurai K, Mani G, Danasekaran R. Recurring tragedy of road traffic accidents in India: Challenges and opportunities. Indian J Crit Care Med. 2015;19(7):434.

12) Sharma $M$, Sudhir $P$, Banu $H$, Chakrabarthy $N$, Kumar R, Mehrotra S, et al. Inclination to speeding and its correlates among two-wheeler riding Indian youth. Ind Psychiatry J. 2014;23(2):105. 